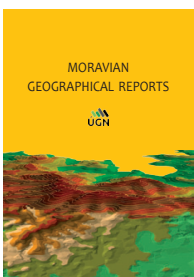

MORAVIAN GEOGRAPHICAL REPORTS

The Czech Academy of Sciences, Institute of Geonics

journal homepage: http:/www.geonika.cz/mgr.html

doi: https://oi.org/10.2478/mgr-2020-0019

\title{
Travel diaries, GPS loggers and Smartphone applications in mapping the daily mobility patterns of students in an urban environment
}

\author{
Stanislav KRAFT ${ }^{\text {a }}$, Tomáš KVĚTOŇ ${ }^{\text {b }}$, Vojtěch BLAŽEK ${ }^{a}$, Lukáš POJSL ${ }^{\text {a }}$, Jiří RYPL ${ }^{\text {a }}$
}

\begin{abstract}
Mapping the daily spatial mobility of university students in an urban environment is the focus of this paper. It uses the city of České Budějovice in the Czech Republic as a case study, employing three different research tools - travel diaries, GPS loggers and Smartphone applications. We focus our attention on the analysis of spatial patterns of mobility using basic mobility indicators (distance, number of daily trips, time spent mobility), travel behaviours (use of transport modes) and the detection of time-space bundles (spaces of concentration of particular time-space trajectories) within the city. We identified four main time-space bundles. Then we compare the three main research methods according to their tracking accuracy and informative value. The Smartphone applications (using the A-GPS technology) provided the best results for the spatial mobility of respondents, although the travel diaries method is still unique due to the extent of some socio-demographic and transport characteristics.
\end{abstract}

Keywords: spatial mobility, travel diaries, GPS loggers, Smartphone applications, 3D visualisation, students, Czech Republic

Article history: Received 30 August 2019, Accepted 20 August 2020, Published 31 December 2020

\section{Introduction}

Mobility is an intrinsic and integral part of most peoples' lives. Workers, managers, students, pensioners, tourists and most other groups of a population are currently characterised by a high level of mobility. By the realisation of various travels, people satisfy their living needs and wishes. The places whereby satisfying the essentials of life, however, have become more and more widespread in the last few decades. Thus, people are forced to travel longer distances and spend more time travelling than before (see e.g. Cresswell, 2006). Such growing mobility is typical for all parts of the world, even though rather large differences occur among them.

Traditionally, inhabitants of regions with a high degree of economic and social development show the highest degree of mobility; on the other hand, even in developing countries the level of spatial mobility has started to grow in importance (Gough, 2008; Adey, 2017). Similar trends can be also tracked down to the level of daily spatial mobility (e.g. Hjorthol et al., 2010). As a result, contemporary society is frequently labelled as highly mobile and dependent on transport (Kaufmann, 2002). From such comments, it is evident that the world is becoming more and more mobile. A geographical point of view would stress the importance of the growing level of mobility, as it has a whole array of spatial associations and impacts (e.g. Kraft and Vančura, 2009).

This article has several objectives. The major goal is to map the daily spatial mobility of students in an urban environment using a case study of university students in the city of České Budějovice, Czech Republic. We focus primarily on the analysis of time-space mobility patterns and the identification of crucial factors in this mobility a classical issue of research not only in transport or human geography (e.g. Urry, 2002; Novák and Sýkora, 2007). This topic is interesting primarily with respect to current changes in post-socialist cities connected to the growth of student concentrations, and the related social, cultural and economic changes in their internal structure (the socalled "studentification": see Smith and Hubbard, 2014).

\footnotetext{
${ }^{a}$ Department of Geography, Faculty of Education, University of South Bohemia, České Budějovice, Czech Republic (*corresponding author: S. Kraft, e-mail: kraft@pf.jcu.cz)

b Department of Social Geography and Regional Development, Faculty of Science, Charles University, Prague, Czech Republic
} 
University students are an interesting and important part of the urban population, although they are rather hidden in most official statistics. The second aim of this article is to compare traditional and novel methods of mapping spatial mobility through travel diaries, GPS loggers, and Smartphone applications. Whereas classical methods consisted of filling in travel diaries and subsequently analysing them using traditional methods of time-space mobility observation (e.g. Anderson, 1971; Janelle et al., 1988), modern methods are associated with the application of modern geo-information technologies (GPS loggers, Smartphones, etc.). Such methods then offer a distinct benefit in the opportunity to obtain a relatively large volume of information, which is moreover precisely localised (Novák et al., 2013), even though large differences exist in the informative value of the data so obtained. Hence, we strive to compare individual methods with respect to obtaining relevant information for the subsequent study of spatial mobility.

The results of the research can be used both in basic and applied arenas. Not only does the article highlight significant aspects of the spatial and temporal organisation of the student population in specific parts of the urban region, but it also analyses primarily the spatial patterns of the students' mobility with an emphasis on creating time-space bundles. In this study, we wanted to answer the following research questions:

- Are there any specifics of students' mobility compared to other population groups?

- What time-space bundles can we identify based on students' mobility in an urban environment?

- Which research method is the most suitable for mapping the students' mobility?

Therefore, the topic is not only important in human geography, but at the same time is also relevant for sociology, economics, cultural anthropology, and others. The research also has a significant application potential, primarily for urban planning and public transport planning, as well as for marketing companies. We follow a classical structure: this introduction is followed by a theoretical framing of spatial mobility issues, emphasising the changing forms of spatial mobility and opportunities to trace them through classical and modern research methods. The research design is introduced in the methodology section. The following parts analyse the time-space mobility of students in the city of České Budějovice, and primarily we accent the benefits and drawbacks of the chosen methods. The conclusion then contains a summary of the complete set of issues, including recommendations for subsequent basic and applied research.

\section{Theoretical background}

Mobility is a multi-disciplinary area of study. Processes related to the mobility of people are thus at the centre of interest of a variety of scientific disciplines, with geography, economics, sociology, cultural studies, etc. assuming leading positions (Kaufmann et al., 2004). Widely-interpreted spatial mobility is then one of key concepts of various sub-disciplines of Human Geography, especially transport geography in studying various aspects of spatial mobility in a complex form. Daily mobility is a relatively frequent topic in such disciplines (see for example: Timmermans et al., 2003; Scheiner, 2006; Klapka et al., 2014; Lefebvre, 2004; Mulíček et al., 2016; Kraft, 2014). For these reasons, we focus our attention on the recent development of spatial mobility and new research methods in this field.
An important inspiration platform of daily mobility research is based on time-geography approaches. The elements of this platform are related to the studies by Hägerstrand (1982) and the so-called Lund School scholars (Pred, 1981; Ellegård, 1999). Time-geography investigates the forms of individual mobilities in space and time, given that time and space are non-separable and quantifiable values that are fitting for the study of the socio-spatial organisation of society. One of the most significant applications of timegeography in practice is the research on the time-space activities of individuals, used for transport planning needs and the optimisation of transport processes within urban areas (e.g. Liu et al., 2015). Czech examples of the application of time-geography methods in studying the daily mobility of inhabitants are seen in studies of the suburban areas of Prague and in rural areas, addressed by Novák and Sýkora (2007) and Temelová et al. (2011), respectively.

Some of the most important factors that have an influence on the intensity, periodicity, level and reasons for daily mobility, are the conditionalities associated with the geographical environment. Some regions (rural, city, small town, suburban) may also be considered, given their distinctive socio-economic conditions and their effects on the level of spatial mobility and the demand for it. In this context, Pucher and Renne (2005) and Nutley (2005) state that the need for higher mobility is a characteristic feature of non-urban areas as the people living there are forced to satisfy their common everyday needs, as a rule, in towns and cities at a distance. Similarly, an increased demand for mobility can be seen newly exhibited in suburban areas where residents, in some cases, have to rely on services and other socio-economic activities located in the central towns (Jones et al., 2000). Urban areas are traditionally characterised by a relatively lower demand for spatial mobility, as especially in minor towns some activities are localised at a relatively short walking distance from residential districts. On the other hand, however, some authors note that urban regions in particular are often characterised by the highest rates of car ownership and the current urban way of living is commonly linked to the high frequency of spatial mobility and use of car transport (e.g. Jensen, 2009). The study by Novák et al. (2012) comments that traditional socio-demographic categories used in studying daily mobility (age, education, sex, etc.) are being overlapped by new distinguishing levels (lifestyle, individual life attitudes), which generally makes their interpretation more difficult.

A great attention of current mobility research is oriented to the study of individual mobility patterns. Their detailed study in recent years is possible due to the spread of modern geoinformation technologies capable of recording individual trajectories (mobile 'phones, GPS devices, location-based services, etc.). Mobility is very complicated and complex phenomenon, however. The results of particular studies differ significantly. Some of them confirm the expected increasing spatial dispersion of individual mobility associated with changes in the spatial organisation of society (e.g. increasing polycentricity of the settlement system: see Schwanen et al., 2001; Gutiérrez and García-Palomares, 2007). Also, Novák et al. (2012) in their study, confirm that the growing differences in mobility patterns are influenced mostly by lifestyle and individual preferences. On the contrary, there are many studies that confirm the relatively high regularity of mobility patterns (e.g. Kraft and Marada, 2017). González et al. (2008), for example, studied the mobility of 100,000 randomly selected individuals during a six-month period. 
The results from this research showed that the monitored trajectories show a high degree of spatial and temporal regularity. Similarly, Song et al. (2010) concluded their research with the statement that more than 90 percent of human mobility patterns are regular and predictable.

In comparison, we note that individual mobility patterns are influenced by many factors. For example, Hunecke et al. (2010) state that individual mobility behaviour is influenced mainly by personal factors (accessibility of transport modes, socio-demographic aspects, lifestyle, etc.) and external factors (location of opportunities, the natural environment, transport policy, etc.). The interaction between these factors is then crucial for the emergence of complex mobility patterns. One of the most important factors affecting the intensity of daily mobility is then the distance over which people must travel to satisfy their living needs and wishes (Herder and Siehndel, 2012). This phenomenon is well known as the distance decay function (see for example, Halás and Kraft, 2016). This discussion can be concluded by saying that mobility is a crucial aspect of peoples' daily lives, with important social and spatial dimensions. Thus, we can better understand society and society-related processes through the study of mobility.

Travel diaries are one of the classical methods of data collection for the time-space mobility of respondents. Among their benefits is primarily the fact that they are able to provide a relatively broad volume of information on the individual trips of respondents, their time-space organisation and the transport behaviour of respondents, including very useful socio-economic parameters of individuals. On the other hand, the relatively low precision of recorded trips and the large time demands for the organisation and evaluation of individual travel diaries, are some of their drawbacks.

More recent studies dealing with practical timegeography applications point to a new era of research techniques in time-geography, which is directly related to the spread of information and communications technologies (Murakami and Wagner, 1999). Improved information and communication technologies (ICTs), widespread mobile communications equipment and satellite navigation systems entail new impulses for research in the field of daily mobility. Such research lies in the analysis of precisely recorded spatio-temporal mobility trajectories using the GPS technology (Novák et al., 2013; Šveda and Madajová, 2012). These studies, nonetheless, show that highly accurate data on mobility (GPS or cell 'phone records), combined with the traditional time-geography techniques (travel diaries, activity diaries), is ideal for mobility research at this time (e.g. Draijer et al., 2000; Kwan and Weber, 2010; Van Der Spek et al., 2009).

Given the recent rapid development of geo-information technologies, attention is, therefore, focused on using localisation data. Hence, recent studies frequently deal with spatial mobility analysis and transport behaviour of respondents using GPS loggers (e.g. Bohte and Maat, 2009), mobile 'phone applications (Abdulazim et al., 2013; Nitsche et al., 2014; Ouředníček et al., 2018), and, predominantly, using big data in the form of the location data of mobile operators (e.g. Widhalm et al., 2015; Calabrese et al., 2013). These precisely localised data provide important information on individual trips and their time-space organisation. GPS loggers and smartphone applications also feature some drawbacks - the difficulty in collecting and processing data files, including their conversion, the discipline of respondents in turning on/off instruments, etc. As a rule, they are applied to selected samples of the population, which is associated with the need for additional aggregation of socio-economic data.

\section{Data and methods}

\subsection{Geographical context}

With respect to the above-discussed prospects and limitations of tracing spatial mobility, we use various methods and data sources. We trace the spatial mobility of university students in the city of České Budějovice, which is the regional metropolis of Southern Bohemia. As of $1^{\text {st }}$ January 2018, the population of the city was 93,863 . The urban population increases daily, however, by school pupils, university students, commuters, visitors, among others, etc. There are three university-type institutions in the city: University of South Bohemia (hereinafter referred to as USB); the Institute of Technology and Business; and The College of European and Regional Studies. In 2017, 14,864 students attended all the university-type institutions in the city. This situation underlines the fact that the city of České Budějovice is a significant and dynamically developing student city: i.e. the student population forms a significant part of the city population.

\subsection{Research methods and data processing}

For mapping individual mobility in the city, we used (i) travel diaries, (ii) GPS loggers, and (iii) localisation data through smartphone applications. For our purposes, the spatial mobility of 140 university students ( 74 female and 66 male) in the territory of the city of České Budějovice was analysed. The research included students from all the university-type institutions in the city. The structure of the sample corresponded to the typical structure of university students in the city with respect to their gender and age (see the official statistics by the Ministry of Education, Youth, and Sports - www.czso.cz). Our effort was to monitor the ordinary mobility of respondents on common working days. We wanted to avoid various limiting and distortion factors of their mobility (weather conditions, extraordinary situations, etc.). For such reasons, we always monitored the daily mobility of each respondent by all three methods, during four working days, in three different weeks. Due to the extent of the monitored sample, the field research was carried out in the period from October 2017 to May 2018.

The data obtained were subsequently geo-referenced and geo-coded. After the field research, data from the travel diaries were digitised for the analytical part of the work. At the same time, each respondent had on him/her a Holux M-1000C or Phototrackr DPL 900 GPS logger on monitored days, which recorded his/her location. Given the battery duration (c. 17 hours), respondents were asked to turn them on immediately after waking up and turn them off at the moment they finished their last trip. Data from GPS loggers in the GPX format were then analysed in ArcGIS 10.5.1 and ArcScene 10.5.1 programs. The data collection using smartphone apps was organised in a similar fashion. Respondents downloaded the respective pre-selected application for recording the time-space location of their phones and turned it on for the given day. For the data collection from smartphones, the Geo Tracker (Android), Trails (iOS), and Sportrate (Blackberry) apps were used. The fact that they provide the user with data exported in GPX format is a significant benefit. Therefore, the data obtained could be compared immediately to data from the GPS loggers with no major adjustments. 


\section{Daily mobility patterns of students in the urban environment}

The daily spatial mobility of individuals is influenced significantly by a large set of both objective and subjective factors. Therefore, each individual is a quite unique entity with specific traits of individual mobility. Nevertheless, it is obvious that certain similarities and concurrences occur with respect to the time-space organisation of university students' daily mobility (see Fig. 1).

During the entire research period, a total of 3,236 trips with a duration of more than 914 hours were recorded for all the respondents, who travelled more than 4,446 kilometres during these trips. That means that each respondent made on average almost six trips in one day (trips were differentiated as to their purpose); the average daily distance was nearly 8 kilometres; and students were mobile almost 98 minutes daily on average. When compared to information for the entire population in various regions in the Czech Republic (all age categories), it can be stated that the spatial mobility of students is extraordinarily high with respect to the number of trips, at shorter distances and, on the contrary, a longer time spent being mobile (see the comparison with Novák and Temelová, 2012, or Kraft, 2014). We assume that this results generally from their usual time-space routines, without the need to take care of members of their households, lower requirements for mobility time aspects and other factors (see for example: Frantál and Klapka, 2020).

Higher values of mobility (the number of trips, distance and time) is more typical for women than that for men (see Tab. 1). These results can be supported by other statistical information (e.g. the standard deviation is similar for both sexes). These gender differences confirm results from other studies, for example Frändberg and Vilhelmson (2011). It can be assumed that the higher mobility of women is influenced by their more active use of space, the higher spatial dispersion of their daily activities, or by selecting a route that is not always the shortest trajectory between two locations (compare, say with Klapka and Roubalíková, 2010). Also, the speed of movements differs by gender, with a higher average speed typical for men $\left(5.14 \mathrm{~km} \cdot \mathrm{h}^{-1}\right)$ compared to women $\left(4.82 \mathrm{~km} \cdot \mathrm{h}^{-1}\right)$. These differences are influenced mainly by the differences in the use of transport modes (see below).

It is obvious from the completed travel diaries that pedestrian, bicycle and public transport are the dominant transport modes. This is particularly influenced by the lower levels of car ownership, the relatively small size of the city allowing easy accessibility to the majority of routine

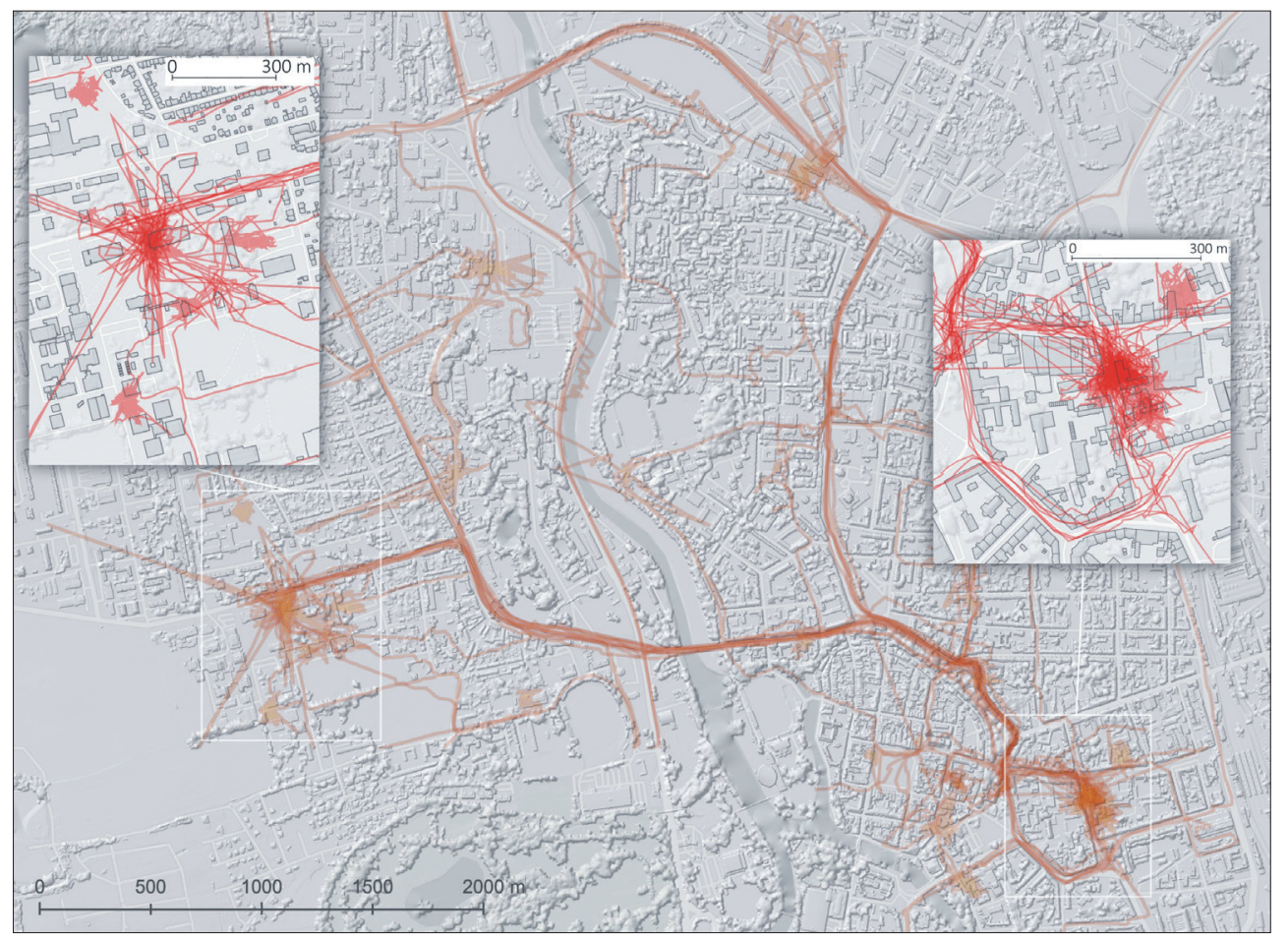

Fig. 1: Visualisation of selected trajectories of spatial mobility of university students within the city $(n=140)$ Source: authors' field research

\begin{tabular}{lcccc}
\hline & Whole sample & $\begin{array}{c}\text { Average } \\
\text { per student }\end{array}$ & $\begin{array}{c}\text { Average for } \\
\text { female students }\end{array}$ & $\begin{array}{c}\text { Average for } \\
\text { male students }\end{array}$ \\
\hline Number of trips & $3,236.0$ & 5.78 & 6.01 & 5.42 \\
Duration (min) & $54,852.0$ & 97.95 & 102.41 & 90.69 \\
Distance $(\mathrm{km})$ & $4,446.3$ & 7.94 & 8.24 & 7.76 \\
$\mathrm{n}=140$ & & & & \\
\hline
\end{tabular}

Tab. 1: Basic indicators of spatial mobility of university students $(n=140)$

Source: authors' field research 
destinations on foot or by bike, with a lesser need to organise the trip time (see e.g. Kamruzzaman et al., 2011; Klöckner and Friedrichsmeier, 2011). This is shown in Figure 2. It is quite evident that the students' spatial mobility is strongly tied to the transport modes' accessibility. Whereas the bike and pedestrian transport modes are more used during the day, public transportation and taxis are relatively more used in the evening and during the night? Moreover, these transport modes are more used, as shown in the travel diaries, for random/irregular trips.

From a spatial point of view, a significant concentration at individual stations is one of the basic attributes of the students' mobility. Visualisation of individual mobility trajectories of students indicates a straightforward concentration at stations associated with routine activities of students (university, campus, city centre, shopping centres, sports fields and others.). Figure 3 shows the spatial attributes of students' mobility in the city during a working day, using 3D visualisation for selected trajectories on $9^{\text {th }}$ April, 2018. The key finding is, of course, that the places of concentration of individual trajectories more or less differ with respect to their time organisation. Therefore, individual mobility trajectories tend to converge in certain time and space segments and, thus, create time-space bundles in which their everyday life is concentrated (Miller, 2005). Thus, the phenomenon arises when several individuals share almost identical activities at a certain time and in one place, a similar finding to Shaw and Yu, 2009. In our research, the time-space bundles were defined according to the following criterion: A time-space bundle was a place where at least $15 \%$ of the respondents concentrated in an area of 100 square metres within one hour. The time-space bundles defined this way can identify transparently the major places of timespace concentration of students in the city.

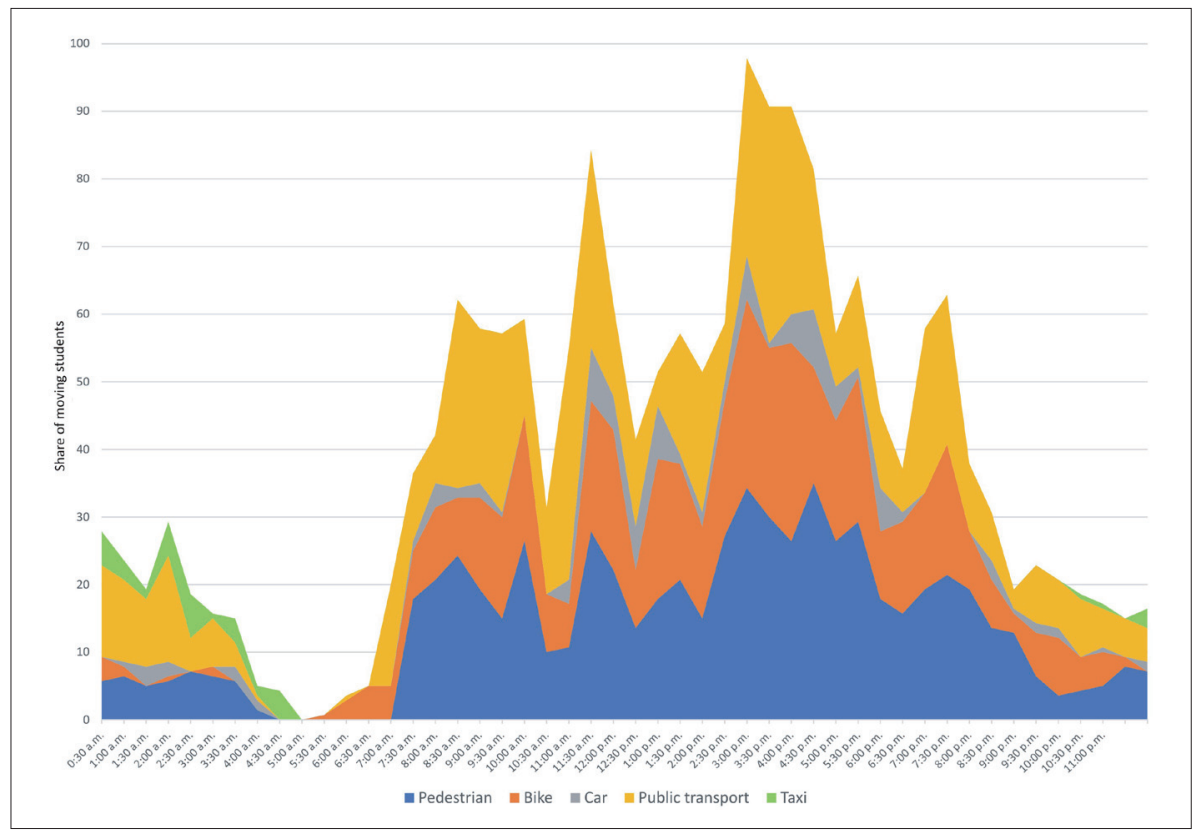

Fig. 2: Transport modes used by students within the city (all monitored days) Source: authors' field research

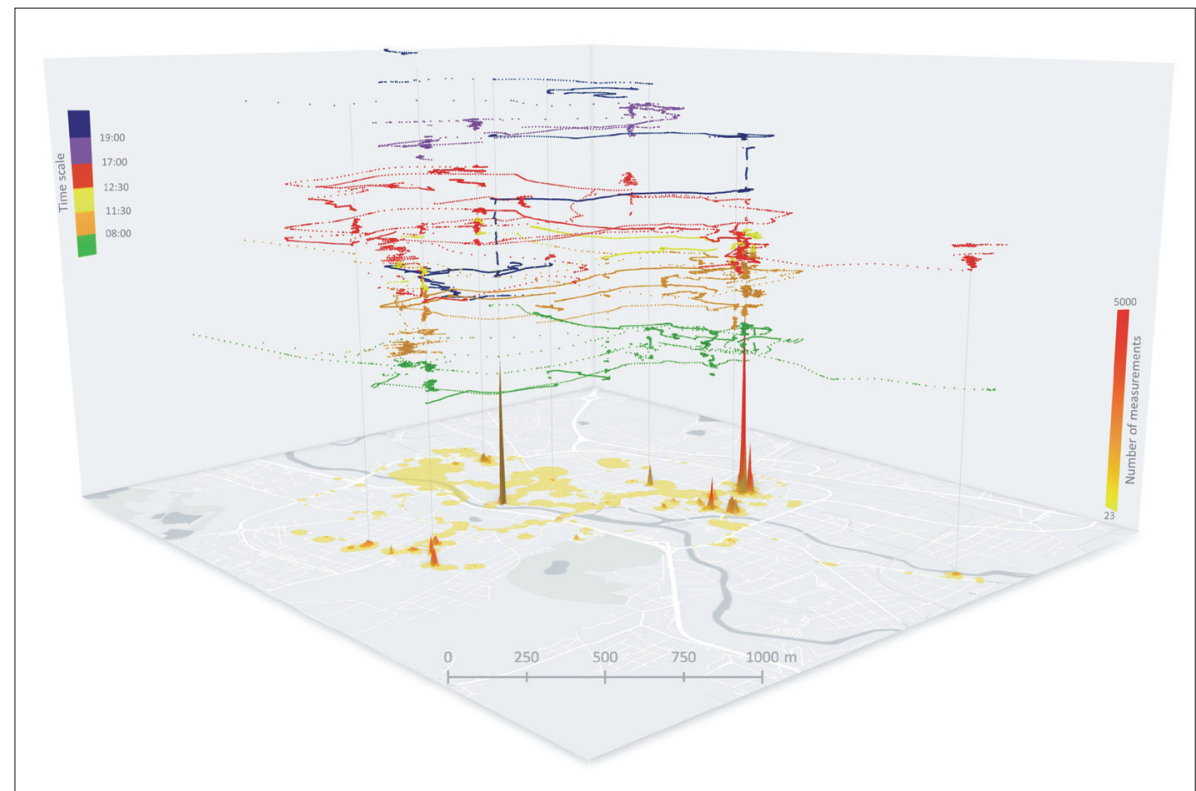

Fig. 3: 3D visualisation of selected trajectories of spatial mobility of university students within the city $\left(9^{\text {th }}\right.$ April, 2018) Source: authors' field research 
In the environment of the city of České Budějovice, four locations - the University campus of USB, the Faculty of Education of USB, the IGY shopping centre, and a less specific area in Senovážné náměstí in the city centre became the major time-space bundles defined in this way. The first two bundles play a key role in the life of students. Within the University campus, there are student dormitories (with an accommodation capacity exceeding 2,000 units), the university canteen, a library, and the majority of USB faculties. Therefore, the majority of students' routine activities occur in this bundle. The Faculty of Education of USB is the largest faculty in the city in terms of the number of students; therefore, it is logical that it becomes an important time-space bundle in the city organism, with a distinctly different concentration of students during the day. Both of these bundles represent a space for the activities of women and men alike. The IGY shopping centre, one of the largest shopping centres in the city, is the third major bundle. Its major benefit consists in its easy accessibility from other bundles, as this shopping centre is located close to the broader city centre (Śilhan and Kunc, 2019). This bundle, however, indicates a relatively specific timespace concentration of students - here, there is an evident preponderance of females, and the major student activities (primarily shopping and entertainment) are concentrated predominantly in the late afternoon and evening hours. Senovážné náměstí, near the historical core of the city, is the last bundle in the students' time-space mobility. In this bundle, the concentration of the students' time-space activity is the lowest, without any distinct irregularities. It can therefore be assumed that the reasons for individual trips differ in this area. This locality is significant because of its proximity to the historical centre and the presence of pubs and entertainment facilities; at the same time, it is one of the key transfer points in terms of public transportation in the city. Activities realised in this bundle are, therefore, of a different nature and relate to both women and men, as reported similarly by Kenna (2011).

\section{Comparison of research methods}

The second major objective of this article is to compare individual research methods - travel diaries, GPS loggers, and records from smartphones. The specifics of individual methods have been indicated above, including their major benefits and drawbacks. In this section, we will try to compare these methods with respect to their precision and the validity of the information obtained. We carry out this comparison with a detailed analysis of the time-space mobility of several respondents. When the whole sample is evaluated, some of the significant aspects, primarily the precision of the information obtained, will remain hidden (Licoppe et al., 2008; Montini et al., 2015). For an illustrative and as clear as possible presentation of the results, two respondents were chosen under their codes $12 \mathrm{M}$ and 16Z. The choice of these two respondents is justified by our intention to obtain a comparison of students as different as possible with respect to their characteristics.

Respondent 12M (a male) is a student at the Faculty of Education of USB. The record on his time-space mobility was obtained on Wednesday 11 October, 2017. On this day, the time-space mobility data collection process was subjected to tracing by all three methods, i.e. travel diaries, GPS loggers, and mobile phones. The travel diary was filled in according to the given criteria. All digital data obtained through the GPS logger and the male respondent's personal mobile phone were faultlessly stored and sent for processing. The respondent's personal mobile phone featured the iOS operating system and his time-space mobility was recorded using the Trails application. The $12 \mathrm{M}$ respondent's spatial mobility consisted of eight trips he made within the time span from 7:25 to 15:10. The second respondent, a female, was chosen under the code 16Z. She was a student of Faculty of Economics at USB. The record on her time-space mobility was obtained on the same day. Her travel diary was completed in compliance with the given criteria, and the same was done for obtaining digital data via the GPS logger and her personal mobile phone, which featured the Android operating system, and her time-space mobility itself was obtained via the Geo Tracker application. 16Z's space mobility consisted of five trips she made in the time span from 9:30 to 17:35.

Figures 4 and 5 show clearly that several differences occurred in the record's quality when both respondents were traced using all three methods. In the travel diaries, respondents filled in the route of the given trips (indicating the streets they went through). It was the individual respondent's responsibility as to how they put this information into their travel diaries. We tried to reconstruct a possible route recorded in this way; however, it was almost impossible regarding the response quality. Therefore, we focused on a more substantial evaluation of differences in the records' quality from GPS loggers and smartphones. These differences are primarily caused by technological dissimilarities in the data collection process.

While the signal from the GPS logger recorded the respondent's position with a lower number of points, the signal from the smartphone was more frequent as far as the number of logged points is concerned (see the comparison of number of points, distance travelled and the divergence between GSM and GPS records in Tab. 2). The reason for this consists in the fact that a GSM (based on the A-GPS technology) logs the respondent's position when any signal is picked up (mobile data, Wi-Fi networks and others.). Also for this reason, recordings from smartphones can be considered more precise. The biggest problems in recording the timespace mobility of the students occurred when the respondent stayed in buildings for a longer time. In buildings, frequent loss of and searching for a signal occurred (the so-called "urban canyoning effect": Gong et al., 2012). As a result, the search for a signal occurred automatically again and tended to generate multiple position data in the vicinity of one place. This was most obvious in the vicinity of individual stations of respondents (generally at home and at school). Multiple recordings of position occurred in both tracing methods. It applies however even in this case that more precise recording (with a lower number of multiple points) is typically provided by smartphones. On the contrary, GPS loggers (without A-GPS technology) had a general tendency to generate more points in one place, which significantly affected the resulting movement trajectory. In such a case, most researchers choose either manual or automatic selection of such points and their reduction for smoothing individual trajectories (Šveda and Madajová, 2015). These corrections are then necessary also in the case of data from smartphones but, of course, on a much lower scale.

In addition to these differences, partial variations of positioning points occurred on passable lines, which is again the result of the above-mentioned 'urban canyoning' effect. Although precise localisation of respondents obtained from a smartphone or GPS logger is very important in time-space mobility research, it still lacks some important aspects 


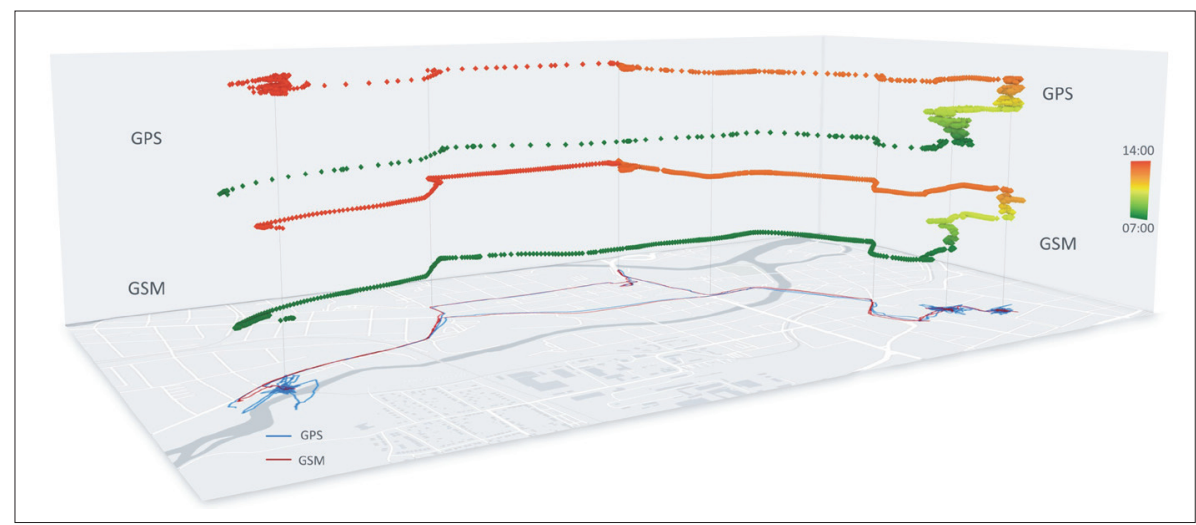

Fig. 4: 3D visualisation and comparison of the trajectories of spatial mobility of respondent $12 M$ within the city Source: authors' field research

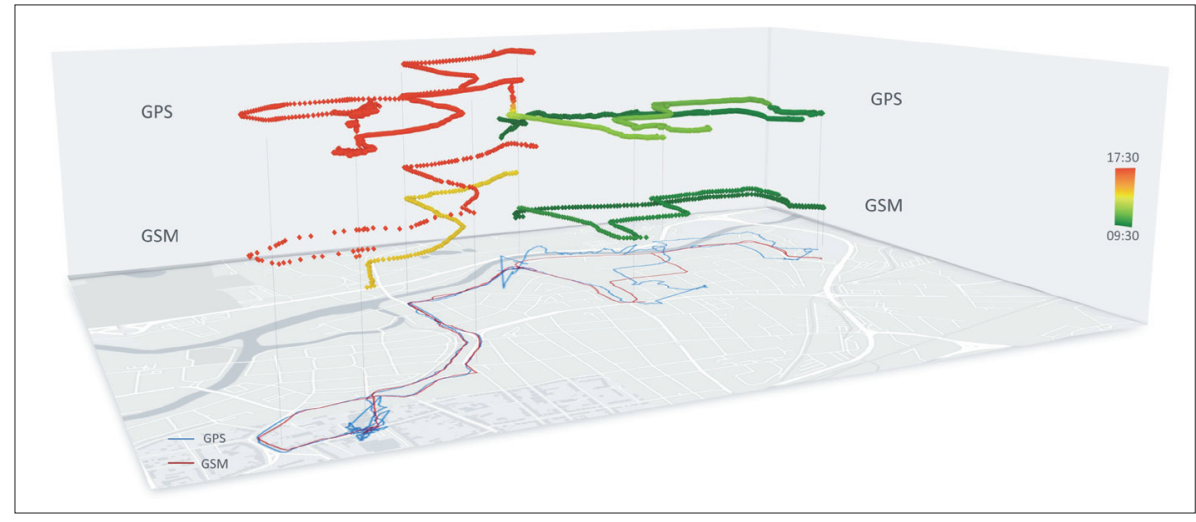

Fig. 5: $3 D$ visualisation and comparison of the trajectories of spatial mobility of respondent $16 Z$ within the city Source: authors' field research

\begin{tabular}{lcccc}
\hline User/record & Points & Distance $(\mathbf{m})$ & \multicolumn{2}{c}{ Divergence GPS on GSM } \\
\hline 12M - GSM & 2,454 & $9,288.74$ & Mean $(\mathrm{m})$ & Median $(\mathrm{m})$ \\
$12 \mathrm{M}$ - GPS & 5,443 & $23,718.52$ & 6.75 & 4.8 \\
$16 \mathrm{Z}$ - GSM & 634 & $8,869.08$ & Mean $(\mathrm{m})$ & Median $(\mathrm{m})$ \\
$16 \mathrm{Z}$ - GPS & 28,179 & $16,731.94$ & 4.62 & 1.95 \\
\hline
\end{tabular}

Tab. 2: Basic features of GSM and GPS records (respondents $12 M$ and 16Z)

Source: authors' field research

identified through travel diaries. Among the most significant pieces of information are the key socio-demographic characteristics of respondents, transport mode, social context of the mobility and other factors. Some research projects are, therefore, focused on eliminating these limitations by, for example, automated identification of the transport mode (Gong et al., 2012; Xiao et al., 2015; Wu et al., 2016) by interconnecting the records with transport networks and an analysis of average speed. The absence of such data, however, remains an unresolved issue in current mobility studies.

\section{Conclusions}

University students are a significant group of the urban population. The general growth in the number of persons studying at universities in urban regions generates new research topics. Among significant topics is the study of student mobility patterns that are applicable in both basic and applied research. It was ascertained in the article that the mobility of university students features some traits (greater number of trips, more time spent on travelling, greater time dispersion and so on) compared to other population groups (Hjorthol et al., 2010). The time-space concentration of mobility into individual bundles is then a specific representational device. Individual bundles are given by the identical organisation of some student time-space mobility routines. Among the most significant bundles of the students' time-space mobility are the university campus, the city centre, shopping centres and other locations. These places play a crucial role in students' everyday activities within the city, and their mobility patterns are substantially influenced by accessibility to transport modes. The use of transport mode differs strongly according to daily time and other specifics. The specific concentration of students within the urban environment brings important findings for policy makers (spatial planning, public transport planning) or taxi services (main origins/destinations within the city, including their time-space organisation). 
The application of various approaches and methods in the research of time-space mobilities of inhabitants is a key prerequisite for extending the borders of this field. The tested methods are unique with respect to their procedures and performance. Therefore, it is impossible to provide a clear-cut verdict which would fully reject or highlight any one of the methods. A significantly more important step is to find a certain intersection across these methods, and, thus, reach an instructive recommendation or guideline for their application in the future. Only a well-chosen combination of all the methods used for collecting time-space data can lead to the required but, primarily, comprehensive results. The questionnaire method offers a value so far unsurpassed in information dealing with the use of modes of transport, trip purpose, and trip periodicity. In the case of a study focused on the nature of smaller groups or households, this method represents an irreplaceable way of bringing exactly targetted knowledge about the studied sample (Novák and Temelová, 2012). In the case of working with digital recording devices, it is necessary to be aware of the helpfulness of the observed sample of the population for these achievements of modern science. The mobile phone method proved itself well in the research of the time-space mobility of university students in České Budějovice and was fully functional in all the cases observed. The GSM records bring more accurate and consistent data. This positive result, however, should not be relied on in all future studies in the topic of time-space mobility observations. Primarily, in a population with a higher age limit, it is necessary to expect major problems when using any technique in the field where there is a lower usage of smart devices. Nevertheless, prospects for improvements in this situation within the overall population are more than favourable. Here, the major benefit, in comparison with other methods, lies with GPS loggers. This benefit is primarily represented by an absolute simplicity in relation to respondents. With the use of modern loggers, much better results in recording time-space data can be envisaged than those presented in this work (Van der Spek et al., 2009). Notwithstanding the financial demands of this method associated with purchasing devices, this way of collecting time-space data has a great potential to include this population group.

\section{Acknowledgement}

This article results from the project: "New Mobility High-Speed Transport Systems and Transport-Related Human Behaviour"; Reg. No. CZ.02.1.01/0.0/0.0/16_026/000 8430, co-financed by the "Operational Programme Research, Development and Education”.

\section{References:}

ABDULAZIM, T., ABDELGAWAD, H., HABIB, K., ABDULHAI, B. (2013). Using Smartphones and Sensor Technologies to Automate Collection of Travel Data. Transportation Research Record, 2383(1): 44-52.

ADEY, P. (2017): Mobility. London, Routledge.

ANDERSON, J. (1971): Space-Time Budgets and Activity Studies in Urban Geography and Planning. Environment and Planning A: Economy and Space, 3(4): 353-368.

BOHTE, W., MAAT, K. (2009): Deriving and validating trip purposes and travel modes for multi-day GPSbased travel surveys: A large-scale application in the Netherlands. Transportation Research Part C: Emerging Technologies, 17(3): 285-297.
CALABRESE, F., DIAO, M., DI LORENZO, G., FERREIRA, J., RATTI, C. (2013): Understanding individual mobility patterns from urban sensing data: A mobile phone trace example. Transportation Research Part C: Emerging Technologies, 26: 301-313.

CRESSWELL, T. (2006): On the Move: Mobility in the Modern Western World. Abingdon, Routledge.

DRAIJER, G., KALFS, N., PERDOK, J. (2000): Global Positioning System as Data Collection Method for Travel Research. Transportation Research Record, 1719(1): 147-153.

ELLEGÅRD, K. (1999): A time-geographical approach to the study of everyday life of individuals - a challenge of complexity. GeoJournal, 48(3): 167-175.

FRÄNDBERG, L., VILHELMSON，B. (2011): More or less travel: personal mobility trends in the Swedish population focusing gender and cohort. Journal of Transport Geography, 19(6): 1235-1244.

FRANTÁL, B., KLAPKA, P. (2020): Exploring the nexus between place of residence, daily activity patterns and the socio-spatial isolation of mothers on parental leave. Area, 52(2): 401-410.

GONG, H., CHEN, C., BIALOSTOZKY, E., LAWSON, C. (2012): A GPS/GIS method for travel mode detection in New York City. Computers, Environment and Urban Systems, 36(2): 131-139.

GONZÁLEZ, M., HIDALGO, C., BARABÁSI, A. L. (2008): Understanding individual human mobility patterns. Nature, 453: 779-782.

GOUGH, K. (2008): 'Moving around': the social and spatial mobility of youth in Lusaka. Geografiska Annaler: Series B, Human Geography, 90(3): 243-255.

GUTIÉRREZ, J., GARCÍA-PALOMARES, J. C. (2007): New spatial patterns of mobility within the metropolitan area of Madrid: Towards more complex and dispersed flow networks. Journal of Transport Geography, 15(1): 18-30.

HÄGERSTRAND, T. (1982): Diorama, Path and Project. Tijdschrift voor economische en sociale geografie, 73(6): 323-329.

HALÁS, M., KRAFT, S. (2016): Modeling and prediction of long-distance traffic flows through the example of road transport in the Czech Republic. Scottish Geographical Journal, 132(1): 103-117.

HERDER, E., SIEHNDEL, P. (2012): Daily and weekly patterns in human mobility. AUM 2012, Workshop on Augmented User Modeling. Extended Proceedings of UMAP 2012.

HJORTHOL, R., LEVIN, L., SIRÉN, A. (2010): Mobility in different generations of older persons: The development of daily travel in different cohorts in Denmark, Norway and Sweden. Journal of Transport Geography, 18(5): 624-633.

HUNECKE, M., HAUSTEIN, S., BÖHLER, S., GRISCHKAT, S. (2010). Attitude-Based Target Groups to Reduce the Ecological Impact of Daily Mobility Behavior. Environment and Behavior, 42(1): 3-43.

JANELLE, D. G., GOODCHILD, M. F., KLINKENBERG, B. (1988): Space-Time Diaries and Travel Characteristics for Different Levels of Respondent Aggregation. Environment and Planning A: Economy and Space, 20(7): 891-906. 
JENSEN, O. (2009): Flows of Meaning, Cultures of Movements - Urban Mobility as Meaningful Everyday Life Practice. Mobilities, 4(1): 139-158.

JONES, L., DAVIS, A., EYERS, T. (2000): Young people, transport and risk: comparing access and independent mobility in urban, suburban and rural environments. Health Education Journal, 59(4): 315-328.

KAMRUZZAMAN, M., HINE, J., GUNAY, B., BLAIR, N. (2011): Using GIS to visualise and evaluate student travel behaviour. Journal of Transport Geography, 19(1): 13-32.

KAUFMANN, V. (2002): Re-Thinking Mobility: Contemporary Sociology. New York, Routledge.

KAUFMANN, V., BERGMAN, M., JOYE, D. (2004): Motility: mobility as capital. International Journal of Urban and Regional Research, 28(4): 745-756.

KEENA, T. (2011): Studentification in Ireland? Analysing the impacts of students and student accommodation on Cork City. Irish Geography, 44(2-3): 191-213.

KLAPKA, P., ROUBALÍKOVÁ, H. (2010): Places and students in urban environment: A time-geographical perspective. Geografický časopis, 62(1): 33-47.

KLAPKA, P., HALÁS, M., ERLEBACH, M., TONEV, P. BEDNÁŘ, M. (2014): A multistage agglomerative approach for defining functional regions of the Czech Republic: the use of 2001 commuting data. Moravian Geographical Reports, 22 (4): 2-13.

KLÖCKNER, C., FRIEDRICHSMEIER, T. (2011): A multilevel approach to travel mode choice - How person characteristics and situation specific aspects determine car use in a student sample. Transportation Research Part F: Traffic Psychology and Behaviour, 14(4): 261-277.

KRAFT, S. (2014): Daily spatial mobility and transport behaviour in the Czech Republic: Pilot study in the Písek and Bystřice nad Pernštejnem regions. Human Geographies - Journal of Studies and Research in Human Geography, 8(2): 51-67.

KRAFT, S., VANČURA, M. (2009): Geographical organisation of the transport system in Czechia and its development in the transformation period. Geografie, 114(4): 298-315.

KRAFT, S., MARADA, M. (2017): Delimitation of Functional Transport Regions: Understanding the Transport Flows Patterns at the Micro-regional Level. Geografiska Annaler: Series B, Human Geography, 99(1): 79-93.

KWAN, M. P., WEBER, J. (2003): Individual Accessibility Revisited: Implications for Geographical Analysis in the Twenty-first Century. Geographical Analysis, 35(4): 341353.

LEFEBVRE, H. (2004): Rhythmanalysis: Space, Time and Everyday Life. New York, Continuum.

LICOPPE, C., DIMINESCU, D., SMOREDA, Z. ZIEMLICKI, C. (2008): Using mobile phone geolocalisation for 'socio-geographical' analysis of coordination, urban mobilities, and social integration patterns. Tijdschrift voor economische en sociale geografie, 99(5): 584-601.

LIU, X., YAN, W. Y., CHOW, J. (2015): Time-geographic relationships between vector fields of activity patterns and transport systems. Journal of Transport Geography, 42(1): 22-33.
MILLER, H. J. (2005): A Measurement Theory for Time Geography. Geographical Analysis, 37(1): 17-45.

MONTINI, L., PROST, S., SCHRAMMEL, J., RIESERSCHLÜSSER, N., AXHAUSEN, K. (2015): Comparison of Travel Diaries Generated from Smartphone Data and Dedicated GPS Devices. Transportation Research Procedia, 11: 227-241.

MULÍČEK, O., OSMAN, R., SEIDENGLANZ, D. (2016). Time-space rhythms of the city - The industrial and postindustrial Brno. Environment and Planning A: Economy and Space, 48(1): 115-131.

MURAKAMI, E., WAGNER, D. P. (1999): Can using global positioning system (GPS) improve trip reporting? Transportation Research Part C: Emerging Technologies, 7(2-3): 149-165.

NITSCHE, P., WIDHALM, P., BREUSS, S., BRÄNDLE, N., MAURER, P. (2014): Supporting large-scale travel surveys with smartphones - A practical approach. Transportation Research Part C: Emerging Technologies, 43(2): 212-221.

NOVÁK, J., SÝKORA, L. (2007): A city in motion: time-space activity and mobility patterns of suburban inhabitants and the structuration of the spatial organization of the Prague metropolitan area. Geografiska Annaler: Series B, Human Geography, 89(2): 147-168.

NOVÁK, J., TEMELOVÁ, J. (2012): Každodenní život a prostorová mobilita mladých Pražanů: pilotní studie využití lokalizačních dat mobilních telefonů. Sociologický časopis/Czech Sociological Review 48(5): 911-938.

NOVÁK, J., AHAS, R., AASA, A., SILM, S. (2013): Application of mobile phone location data in mapping of commuting patterns and functional regionalization: a pilot study of Estonia, Journal of Maps, 9(1): 10-15.

NUTLEY, S. (2005): Monitoring rural travel behaviour: a longitudinal study in Northern Ireland 1979-2001. Journal of Transport Geography, 13(3): 247-263.

OUŘEDNÍČEK, M., NEMEŠKAL, J., ŠPAČKOVÁ, P., HAMPL, M., NOVÁK, J. (2018): A synthetic approach to the delimitation of the Prague Metropolitan Area, Journal of Maps, 14(1): 26-33.

PRED, A. (1981): Social Reproduction and the TimeGeography of Everyday Life. Geografiska Annaler. Series B, Human Geography, 63(1): 5-22.

PUCHER, J., RENNE, J. (2005): Rural mobility and mode choice: Evidence from the 2001 National Household Travel Survey. Transportation, 32(2): 165-186.

SCHEINER, J. (2006): Housing mobility and travel behavior: A process-oriented approach to spatial mobility. Evidence from a new research field in Germany. Journal of Transport Geography, 14(1): 37-46.

SCHWANEN, T., DIELEMAN, F., DIJST, M. (2001): Travel behaviour in Dutch monocentric and policentric urban systems. Journal of Transport Geography, 9(3): 173-186.

SHAW, S., YU., H. (2009): A GIS-based time-geographic approach of studying individual activities and interactions in a hybrid physical-virtual space. Journal of Transport Geography, 17(2): 141-149.

SMITH, D., HUBBARD, P. (2014): The segregation of educated youth and dynamic geographies of studentification. Area, 46(1): $92-100$. 
SONG, C., QU, Z., BLUMM, N., BARABÁSI, A. L. (2010): Limits of Predictability in Human Mobility. Science, 327(5968): 1018-1021.

ŠILHAN, Z., KUNC J. (2020): Two decades of changes in spatial distribution of retail and commercial services: Czech experience. Hungarian Geographical Bulletin, 69(1): 41-55.

ŠVEDA, M., MADAJOVÁ, M. (2015): Merging diaries and GPS records: The method of data collection for spatiotemporal research. Moravian Geographical Reports, 23(2): 12-25.

TEMELOVÁ, J., NOVÁK, J., POSPÍŠILOVÁ, L., DVOŘÁKOVÁ, N. (2011): Každodenní život, denní mobilita a adaptační strategie obyvatel v periferních lokalitách. Sociologický Časopis/Czech Sociological Review, 47(4): 831-858.

TIMMERMANS, H., WAERDEN, P., AELVES, M., POLAK, J., ELLIS, S., HARVEY, A., KUROSE, S., ZANDEE, R. (2003): Spatial context and the complexity of daily travel patterns: an international comparison. Journal of Transport Geography, 11(1): 37-46.
URRY, J. (2002): Mobility and Proximity. Sociology, 36(2): 255-274.

VAN DER SPEK, S., VAN SCHAICK, J., DE BOIS, P., DE HAAN, R. (2009): Sensing Human Activity: GPS Tracking. Sensors, 9: 3033-3055.

WIDHALM, P., YANG, Y., ULM, M., ATHAVALE, S., GONZÁLEZ, M. (2015): Discovering urban activity patterns in cell phone data. Transportation, 42(4): 597-623.

WU, L., YANG, B., JING, P. (2016): Travel Mode Detection Based on GPS Raw Data Collected by Smartphones: A Systematic Review of the Existing Methodologies. Information, 7(4): 67.

XIAO, G., JUAN, Z., ZHANG. C. (2015): Travel mode detection based on GPS track data and Bayesian networks. Computers, Environment and Urban Systems, 54: $14-22$

\section{Please cite this article as:}

KRAFT, S., KVĚTOŇ, T., BLAŽEK, V., POJSL, L., RYPL, J. (2020): Travel diaries, GPS loggers and Smartphone applications in mapping the daily mobility patterns of students in an urban environment. Moravian Geographical Reports, 28(4): 259-268. Doi: https:// doi.org/10.2478/mgr-2020-0019 